\section{$\triangle 91$}

ADIPOSE TISSUE FAT COMPOSITION MEASURED BY CARBON 13 MAGNETIC RESONANCE SPECTROSCOPY. Don Hanrahan, Louise Thomas*, Jimmy Bell**, Denis Azzopardi, Janet Sargentoni*, Maria Barnard*, David Bryant*, Graeme Bydder*, David Edwards. Department of Paediatrics and Neonatal Medicine, and the *Robert Steiner MR Unit, Royal Postgraduate Medical School, London.

Natural abundance carbon 13 magnetic resonance spectroscopy $\left({ }^{13} \mathrm{C}\right.$ MRS) allows the proportion of saturated and unsaturated fatty acids in adipose tissue to be measured repeatedly and non-invasively. Eleven infants and two of their mothers underwent ${ }^{13} \mathrm{C}$ MRS. Ten infants were studied in the first week of life, one also at 6 weeks and one at 10 weeks only. Using an enveloping transmitter coil and a surface receiver coil, coupled ${ }^{13} \mathrm{C}$ spectra were obtained with repetition times of 0.3 seconds and 30 seconds. These were analysed by the NMR1 curve fitting program and the percentages of saturated and unsaturated fatty acids calculated. The results are shown either individually or as the median and range in the table:

$\begin{array}{lllll}\text { Infants } & \begin{array}{l}\text { Gestation } \\ \text { (wseks) }\end{array} & \begin{array}{l}\text { Birth weight } \\ \text { (kg) }\end{array} & \begin{array}{l}\text { Unsaturated } \\ \text { fatty acids }(\%)\end{array} & \begin{array}{l}\text { Saturated } \\ \text { fatty acids (\%) }\end{array} \\ \text { Preterm }(n=3) & 33 & 1.94(1.8-2.25) & 49(41-58) & 51(42-59) \\ \text { Tern }(n=7) & 38(37-40) & 3.1(2.0-3.5) & 55(38-64) & 45(36-62) \\ \text { Post-neonatal }(n=2) & 40,41 & 3.1,3.2 & 60,83 & 40,17\end{array}$

One of the two mothers studied, a vegan, had a higher proportion of unsaturated fatty acids compared to the other mother who consumed a mixed diet $(87 \%$ vs $71 \%)$. These preliminary results suggest that ${ }^{13} \mathrm{C}$ MRS might be used to perform longitudinal studies of different influences on the composition of adipose tissue in infants.

1 Magnetic Resonance in Medicine, 1992:27:97-106

\section{2}

THYMINE-URACILURIA - A DISEASE OR A FORTUITIOUS FINDING?

Carol ine Haverkorn, Hans K: son Blomquist, Kalle Snellman. Henrik

Ahlman, Ulrika von Döbeln and Lars Hagenfeldt

Department of Clinical Chemistry. Huddinge University Hospital, S.

14186 Huddinge. Sweden

Elevated excretion of thymine and uracil and decreased excretion of 3.aminoisubutyrate was found in three patients.

Patient 1 had seizures at age 2 days and these gradually resolved until 2 years of age when treatment was stopped. Since then he has only had myoclonic jerks during sleep. Repeated EEG recordings have been normal. The boy has a fairly normal mental development but does not speak at four years of age. His father has always had extensive myoclonic jerks during sleep.

Patient 2 is a 5 year old girl with slight motor delay and severe mental retardation. She has had febrile seizures and EEG and a brain CT scan have been normal.

Patient 3 has Krabbe's disease with characteristic symptoms of this disorder.

There is no consistent clinical presentation in the patients detected by metabolic investigation and thymine-uraciluria has been observed in healthy subjects - is the finding pathogenic?

\section{3}

THE USE OF A SPECIFIC IMMUNORADIOMETRIC ASSAY (IRMA) TO DETERMINE NEONATAL INSULIN-GLUCOSE RELATIONSHIPS.

Jane M. Hawdon, Melisa Jarvis, Penny Clark, C. Nick Hales

Neonatal Unit, Liverpool Maternity Hospital, University of Liverpool, and Department of Clinical Biochemistry, University of Cambridge.

Recent studies have shown that neonatal insulin-glucose relationships differ to those of older children. The aim of this study was to determine whether crossreactivity with proinsulin-like molecules accounted for this finding.

Daily venous blood samples were collected from 18 neonates (median gest. 30 weeks) in the first postnatal week. Blood glucose concentration (BG) was determined by microenzymatic methods and plasma concentrations of insulin proinsulin (proins) and des 31,32 split proinsulin (31-32 spl) were measured by specific IRMA.

Mean (sem) $8 G$ was $4.5(0.2) \mathrm{mmol} / /$. Median (range) concentrations for insulin proins and $31-32 \mathrm{spl}$ were 35 (5-199), $12(5-30)$, and 19 (9-44) pmol/1. On multiple regression analysis $B G$ correlated negatively with gestation $(p<0.001)$ and positively with glucose infusion rate $(p<0.01)$; there was a positive correlation between plasm insulin concentration and $B G(p<0.001)$ which was independent of gestational and postnatal age and birthweight standard deviatio; score; and independent negative correlations for proins with gestational and postnatal age $(p<0.01, p<0.01)$

These data suggest that plasma insulin concentrations may be overestimated unless a specific assay is used. The presence of proinsulin in the first postnatal week may indicate immaturity of the neonatal pancreas.

\section{4}

OBSTRUCTIVE SLEEP APNEA SYNDROME (OSAS) IN CHILDREN WITH CRANIOFACIAL ANOMALIES

Philipps-Universität Marburg, Zentrum für Kinderheilkunde, Germany

Introduction: In children craniofacial anomalies may cause airway narrowing and lead to obstructive sleep apnea. The children show noctumal symptoms like sleep disturbances, enuresis, excessive sweating during sleep, nocturnal snoring. The daytime symptoms are ranging from daytime sleepiness, hyperactivity up to pathological shyness and social withdrawal. OSAS may have negative effects on cardiac function and growth. An evaluation to determine the extent of the OSAS is necessary.

Method: We use an nocturnal polygraphic recording (PR) that includes the recording of respiration and nasal airflow monitoring. Furthermore an electrocardiogram and heart rate are determined. Moreover an actigraph reflects movement of the wrist or the legs depending on the sensor's placement. Any intrathoracic pressure changes and transcutaneous oxygen saturation are measured by specific sensors.

Results: 17 children with craniofacial anomalies were examined. 10 of these patients Results: 17 children wh hraniofacial anomalies were examined. 10 of these patients got maxill and after surgery. After surgery 3 of the 4 children demonstrated significant reduction of sleep disturbances and apneas during sleep (mean sleep apnea index (Al) before surgery: 6,7 - vs. Al after surgery: 3,6 ). There exists a PR only after surgery in 6 patients. One in these 6 patients showed an Al $\geq 10$ after surgery (mean Al: 5,8 ). 70 percent of the children with PR before maxillofacial surgery demonstrated major sleep disturbances (mean Al: 16)

Conclusion: The results show the positive effects of maxillofacial surgery if maxillofacial abnormalities are reason for OSAS in children. In such cases surgery may be considered. In order to bridge the time till undergoing maxillofacial surgery, we recommend to use nasal continuous positive aimay pressure to children who require orthodontic preparation.

\section{$\Delta 95$}

EVALUATION OF PLASMA PHENYLLACTATE IN PHENYLKETONURIA Georg F. Hoffmann, Martina Beigl, Ansgar Kutscha and Jochen Pietz. Dept. of Pediat., Univ. Heidelberg, Germany

There is a controversy whether, in addition to phenylalanine (PHE), products of $\mathrm{PHE}$ transamination are involved in the pathogenesis of phenylketonuria (PKU). We determined phenyllactate in plasma by HPLC and PHE by amino acid analysis monthly for half a year in 24 adult patients with classic PKU who had stopped diet. Phenyllactate was measurable in all plasma samples (mean: $52 \mu \mathrm{mol} /$; range: $7-154$; mean $\mathrm{PHE}: 1250 \mu \mathrm{mol} /$; range: 670 -1990). Phenyllactate and PHE were linearly correlated $(r=0.734[n=144$ ] $p<0.0001)$. The correlation was stronger for the PHE level from the same date than for the previous PHE level $(r=0.734$ versus 0.646$)$. This disproves the hypothesis that phenyllactate is a useful parameter of long-term dietary control in PKU. There was a positive correlation between phenyllactate, but not PHE, and quality of dietary control during the first 12 years of age as judged by median values of all quantitative PHE determinations over 24 6 -months periods $(p<0.05)$. We find it difficult to interpret this observation. Patients with higher plasma phenyllactate at a given PHE also tended to have lower IQ values, although this correlation did not reach significance.

From our data regular monitoring of plasma phenyllactate is not indicated in patients with PKU. However, the extent of PHE transamination could be an independent parameter influencing the quality of dietary control. Further correlative studies of mental and biochemical phenotype in PKU patients are indicated and may help to facilitate individual decisions on the necessity and quality of life-long dietary therapy.

ENERGY EXPENDITURE IN VERY LOW BIRTHWEIGHT INFANTS (VLBW) INDIRECT CALORIMETRY VERSUS 2H18O METHOD. G. F. Hoffmann, A Janecke, T. Böhler, B.M.A.A. Verstappen-Dumoulin, D. Rating, O. Linderkamp and G.H. Visser. Dept. of Pediat., Univ. Heidelberg, Germany and Centrum voor Isotopen Onderzoek, Rijksuniversiteit Groningen, The Netherlands

Information on individual energy expenditure should help to meet the specia and increased nutritional needs of VLBW. We evaluated the accuracy, precision and overall performance of a newly designed portable indirec calorimeter (DELTATRAC II, Datex, Helsinki, Finland) in 20 spontaneously breathing VLBW. Initial infant weight, age, and postconceptional age wer (means \pm SD) $1,351 \pm 250 \mathrm{~g}, 3.6 \pm 2.8 \mathrm{wk}$, and $33.9 \pm 2.2 \mathrm{wk}$. Mean values for $\mathrm{O}_{2}$ consumption $\left(\mathrm{VO}_{2}\right), \mathrm{CO}_{2}$ production rate $\left(\mathrm{VCO}_{2}\right), \mathrm{RQ}$, and energy expenditure by indirect calorimetry were (means \pm SD) $7.5 \pm 0.9 \mathrm{ml} / \mathrm{kg} / \mathrm{min}$ $7.4 \pm=0.8 \mathrm{ml} / \mathrm{kg} / \mathrm{min}, 0.99 \pm 0.06$, and $59.6 \pm 6.8 \mathrm{kcal} / \mathrm{kg} / \mathrm{d}$. Although the thermogenic effect of muscular activity on $\mathrm{VO}_{2}$ and $\mathrm{VCO}_{2}$ was clearly demonstrable, mean 24-hour $\mathrm{VO}_{2}$ and $\mathrm{VCO}_{2}$ did not differ from quiet periods Measurements over 6 hours explained $>95 \%$ of the variance of $24 \mathrm{~h}$. In $\$$ infants the $2 \mathrm{H}^{180}$ method was simultaneously applied. Isotope turnover rate of 180 , isotope dilution space of 180 as percentage of total body weight, and $\mathrm{VCO}_{2}$ were (means $\pm \mathrm{SD}$ ) $0.246 \pm 0.021 / \mathrm{d}, 79.6 \pm 4.5 \%$, and $7.6 \pm 1.1 \mathrm{ml} / \mathrm{kg} / \mathrm{mir}$. $\mathrm{VCO}_{2}$ as estimated by indirect calorimetry and $2 \mathrm{H}^{180}$ method differed no more than $12 \%$ in any baby. In conclusion, individual energy expenditure can be reliably determined in VLBW by indirect calorimetry as well as by ${ }^{2} \mathrm{H}^{18} 4$ method. Physical activity scores do not need to be recorded. 